INFORMAL LOGIC

XI.1, Winter 1989

\title{
Favorable Relevance and Arguments
}

\section{GEORGE BOWLES The George Washington University}

Since an argument consists of at least two propositions so related to each other that one (or more) is a premise and the other a conclusion, the definition of an argument consists of one or more conditions that are singly necessary and jointly sufficient for one proposition to be a conclusion and one or more others premises. Concerning these conditions we may ask the following questions:

1. Do they include the actual or attributed favorable relevance' of one or more of the propositions to another?

2. Do they include the assertion of some or all of the propositions?

3. Do they include the actual or attributed verification, as distinguished from explanation, of one proposition by the remainder?

4. Do they include the expression of the propositions in a dialogue?

The purpose of this paper is to answer only the first of these questions.

I. Is the actual or attributed favorable relevance of one proposition to another a necessary condition for the former to be a premise and the latter the conclusion in an argument?

The case for an affirmative answer to this question is that at least part of what it means for a group of propositions to be an argument is that some of those constituents are, or at least are said to be, (good) reasons for another; and whatever is a (good) reason for something else is favorably relevant to it. This proves, or at least suggests, that the actual or attributed favorable relevance of one or more propositions to another is a necessary condition for the former to be a premise and the latter the conclusion in an argument.

On the other side, it might be urged, first, that there can be an argument against as well as for a proposition. When there is, the proposition that the argument is against is the conclusion; and the premises have, or at least are said to have, unfavorable relevance to it. So, here we have an argument whose premises are, or at least are said to be, not favorably but unfavorably relevant to its conclusion. Consequently, one or more propositions' actual or attributed favorable relevance to another is not a necessary condition for the former to be premises and the latter the conclusion in an argument.

But this argument is unsound because it claims that, in the case of an argument against something, the proposition that the argument is against is the same as its conclusion. This is false, since when we argue against something, our conclusion is not the proposition against which we are arguing but rather the claim that that proposition is false, wrong, or something similar. Our premises are, or at least are said to be, favorably relevant to that claim-i.e., to our conclusion - while at the same time they are, or are said to be, unfavorably relevant to the proposition against which we are arguing. For instance, if against the possibility of unaided human flight we argue from premises about the inability of an unaided human being to generate enough lift to overcome gravity, our premises are, or are said to be, unfavorably relevant to the proposi- 
tion against which we are arguing - namely, that human beings can fly without assistance. But at the same time they are, or are said to be, favorably relevant to our conclusion-namely, that it is false that human beings can fly without assistance.

A second argument for the negative answer is this. When we deliberate among alternatives, we construct an argument some of whose premises are, or at least are said to be, favorably, others unfavorably, relevant to the conclusion that one alternative is best. Depending on the relative strength of the premises for and against the conclusion, we accept or reject the conclusion, thereby deciding for or against that alternative. This shows that it is possible for premises to have actual or attributed unfavorable relevance to a conclusion. ${ }^{2}$

The reply to this second argument is that there is a more plausible account of how we reason when we deliberate, according to which we distinguish the alternatives from each other and ascertain all their possible consequences; we note how desirable or undesirable and how probable or improbable are all those consequences; we compare those data about the consequences; and from that comparison we conclude that one alternative is better, or at least not worse, than the remainder. ${ }^{3}$ In this account, no premise is, or is said to be, unfavorably relevant to its conclusion. Deliberation, then, provides no instance of either actual or attributed unfavorable relevance of premises to a conclusion.

The final argument for the negative answer says that some arguments (a species of what are called 'conductive arguments') have conclusions drawn from premises some of which are, or at least are said to be, unfavorably relevant to them. For instance, the text-

Although your lawn needs cutting, you ought to take your son to the movies because the picture is ideal for children and will be gone by tomorrow.

-expresses the argument-
P1. Your lawn needs cutting.

$\mathrm{P} 2$. The picture is ideal for children.

P3. The picture will be gone by tomorrow.

C. You ought to take your son to the movies.

-in which the first premise is, or at least is said to be, unfavorably relevant to the conclusion. ${ }^{4}$

The reply to this is that though 'because' in the text tells us that 'You ought to take your son to the movies' is a conclusion, and 'This picture is ideal for children' and 'The picture will be gone by tomorrow' premises, in an argument, 'although' tells us that between 'Your lawn needs cutting' and 'You ought to take your son to the movies' there is an opposition that is incompatible with their being premise and conclusion in the same argument. This incompatibility may be better appreciated if we remove from the text both 'because' and the premises it indicates:

Although your lawn needs cutting, you ought to take your son to the movies.

This makes it apparent that 'Your lawn needs cutting' and 'You ought to take your son to the movies' are not related as premise to conclusion. Nor do they become so upon the restoration of the removed material.

So, an accurate analysis of the reasoning expressed in the first text would yield two arguments-

A1.

P. Your lawn needs cutting.

(C. You ought not to take your son to the movies.)

A2.

P1. The picture is ideal for children.

$\mathrm{P} 2$. The picture will be gone by tomorrow.

C. You ought to take your son to the movies.

-in neither of which the premises are, or are said to be, unfavorably relevant to the conclusion.

Having now seen that the case for the 
negative answer fails, ${ }^{5}$ we may conclude that one or more propositions must be, or at least be said to be, favorably relevant to another in order for the former to be premises and the latter a conclusion in an argument.

\section{Is the favorable relevance that is a necessary condition for one proposition to be a premise and another the conclusion in an argument actual, or is it attributed? ${ }^{6}$}

Supposing that actual or attributed favorable relevance is a necessary condition for one proposition to be a premise and another the conclusion in an argument, the question remains which kind of favorable relevance is required-actual or attributed. To this question there seem to be just these two answers: either an argument's premises must actually be favorably relevant to its conclusion, or else they must at least be said to be so. If the first of these answers were correct, then a group of propositions would constitute an argument only if some of them (namely, the premises) actually were favorably relevant to another (namely, the conclusion); but if the second answer were correct, then the premises of an argument could fail actually to be favorably relevant to its conclusion-i.e., they could fail actually to make the conclusion either probable or certain-and still be parts of an argument.

Two points of clarification of the second answer are in order. First, it is deliberate that the agent of attribution-i.e., who or what says that some of the propositions are favorably relevant to another-is unspecified. Usually, the most conspicuous such agent would be the arguer-i.e., the person or other rational being who offers the argument. But it need not always be so. Someone may have an argument in mind without accepting or offering it himself, in which case he would not attribute to the premises favorable relevance to the conclu- sion. Moreover, an argument might be expressed independently of any rational agency-e.g., by unusual erosion on a hillside or an improbable arrangement of colored pebbles on a beach-so that no one would attribute favorable relevance to the premises. In such admittedly atypical but possible cases as these, although no arguer attributes to the premises favorable relevance to the conclusion, something else does. In the first case the attribution is done not by the argument's uncommitted contemplator but by a proposition he has in mind (but does not accept) that sums up the whole argument-viz., a proposition that says that the premises are favorably relevant to the conclusion. Similarly, in the second case the attribution is done not by any rational being but again by the proposition that sums up the whole argument and is expressed by the entire text. In fact, even when an arguer is involved, he attributes to the premises favorable relevance to the conclusion only insofar as he believes or expresses a proposition that attributes to the premises favorable relevance to the conclusion. So, in all arguments, one agent of attribution is such a proposition; in most, an additional agent is the arguer.

The second point of clarification is that, even if an arguer attributes to the premises some degree of favorable relevance to the conclusion, he need not say so: his entertainment of the argument may be private, or he may express it without saying just how favorably relevant he thinks the premises are to the conclusion. Where a rational agent of attribution is involved, attributing is one thing and expressing that attribution is another.

So, the second answer claims that an essential feature of an argument is that, whether by rational agency or not, and in the former case whether expressed or not, favorable relevance to the conclusion is attributed to the premises.

Having now clarified the second answer, let us proceed to the arguments that compose the case for the first answer-namely, 
that a group of propositions constitutes an argument only if some of them actually are favorably relevant to another. That case seems to consist wholly in the case against the second answer-namely, that a group of propositions makes up an argument only if some of them are said to be favorably relevant to another. One such argument is that it is sometimes possible to ascertain that someone is arguing from premises to a conclusion but impossible to ascertain whether he thinks that his premises are favorably relevant to his conclusion. For example, if someone had said-

Socrates is mortal. He is a man, and all men are mortal.

-his text would express an argument. But there is no evidence that the author attributed to the premises favorable relevance to the conclusion, since he used no illatives like 'proves' or 'suggests' and no probability-indicators like 'certainly' or 'probably'. It seems, then, that here is an argument whose premises lack attributed favorable relevance to the conclusion. If so, attributed favorable relevance cannot be an essential feature of an argument.

This argument assumes that the only evidence we can have about attributed favorable relevance must consist of verbal clues like illatives or probability-indicators. But this is false: other sources of evidence are possible. For instance, people do not usually neglect or reject the apparent logical relations among the propositions they express by means of sentences that are near each other. So, a person would be unlikely to express together several propositions, some of which would plausibly be reasons for another, unless he thought some of the propositions favorably relevant to the remainder. If so, then we have a source of evidence about attributed favorable relevance beyond verbal clues like illatives and probability-indicators. And this refutes the preceding argument.

A second argument against the second answer is that it is incompatible with for- mal logic. If attributed favorable relevance were a necessary condition for an argument, then in order to ascertain whether a group of propositions constitutes an argument we would usually have to ascertain whether someone attributed to some of them favorable relevance to another. But this is a psychological question and is, as such, alien to formal logic, which is independent of all psychological considerations. So, a definition of an argument in terms of attributed favorable relevance would be incompatible with formal logic.

The reply is that if the second answer is to be rejected because it is incompatible with formal logic, then what makes a group of propositions an argument must be ascertainable on formal grounds alone. Now, on formal grounds alone it is possible to ascertain actual, not attributed, relevance. But whether actual, rather than attributed, favorable relevance is a necessary condition for an argument is the very thing in question. Hence, the argument begs the question by assuming what is to be proved.

A third argument against the second answer is that the attributed favorable relevance of one or more propositions to another is not necessary for the former to be premises and the latter the conclusion in an argument, because there can be an argument in the absence of such attributed favorable relevance. Let $A$ be a Chinese peasant in 932 B.C., let $B$ be a Roman merchant in 106 A.D., and let $C$ be a South African geographer in 1935 A.D. Suppose that $A$ thinks to himself, "All men are mortal". Several centuries later, in ignorance of what $A$ thought, $B$ thinks to himself, "Socrates is a man". And after the lapse of many more centuries, $C$, in ignorance of what $A$ and $B$ thought, thinks to himself, "Socrates is mortal". This example exhibits none of the attributed favorable relevance required by the second answer, yet it does contain an argument, because the propositions that $A$ and $B$ have in mind are actually favorably relevant to the proposition that $C$ has in mind.? 
The reply to this is that, despite the fact that the propositions that $A$ and $B$ have in mind are actually favorably relevant to that which $C$ has in mind, these propositions do not in this case constitute an argument. The contrary impression may arise from the fact that some fourth person, such as the reader, has all three propositions in mind and attributes to some of them favorable relevance to the remainder. ${ }^{8}$ The second answer, then, is not overthrown by this alleged counterexample. ${ }^{9}$

So much for the evidence against the second answer-namely, that a group of propositions constitutes an argument only if some of them are said to be favorably relevant to another-and in favor of the firstnamely, that a group of propositions constitutes an argument only if some of them actually are favorably relevant to another. Now, what is to be said against the first and in favor of the second?

The argument against the first, and in favor of the second, answer goes like this. If the first answer were correct, then the actual favorable relevance of one or more propositions to another would be necessary to make the former premises, and the latter a conclusion, in an argument. But this leads to false consequences. For instance, suppose that someone says, "All men are mortal, and Socrates is mortal; therefore, all men are Socrates'. It seems clear that his use of the illative 'therefore' tells us that he has in mind an argument whose premises are 'All men are mortal' and 'Socrates is mortal' and whose conclusion is 'All men are Socrates'. This is consistent with the second answer, which would say that there is an argument only where there is attributed favorable relevance, and the speaker's use of the illative 'therefore' shows that in this case there is attributed favorable relevance. But it is inconsistent with the first answer, which would say that, because the first two propositions are not actually favorably relevant to the third; and because the actual favorable relevance of one or more proposi- tions to another is necessary in order for the former to be premises, and the latter a conclusion, in an argument; they do not constitute even a bad argument. ${ }^{10}$ According to this answer, the person's use of the illative 'therefore' shows, not that an argument is present (since it does not show that one or more propositions actually are favorably relevant to another), but at most that he is trying to argue. The first answer, then, entails a false, while the second is compatible with a true, conclusion. ${ }^{11}$

This argument, then, concludes that the first answer is false because it entails a false consequence: contrary to what it asserts, actual favorable relevance is not a necessary condition for an argument. So, assuming that the second is the only other answer, it is true: a group of propositions constitutes an argument only if to some of them is attributed favorable relevance to another.

This last argument, I think, settles the question: attributed, rather than actual, favorable relevance is a necessary condition for an argument.

\section{Conclusions}

This paper has reached two conclusions. The first is that the actual or attributed favorable relevance of one proposition to another is a necessary condition of the former's being a premise and the latter the conclusion of an argument, because a group of propositions constitutes an argument only if some of them are, or at least are said to be, (good) reasons for another; and something is a (good) reason for something else only if it is favorably relevant to it. The second conclusion is that attributed, rather than actual, favorable relevance is a necessary condition for an argument. For only thus can we avoid a prohibition against calling some arguments 'arguments'. 


\section{Notes}

1 Any two propositions are such that one is either relevant or irrelevant to the other. If relevant, it is either favorably relevant (in which case it makes the other probable or certain) or unfavorably relevant (in which case it makes the other improbable or impossible). There may be degrees of favorable or unfavorable relevance: one proposition may be more or less favorably or unfavorably relevant to another than a third. Favorable relevance which is said to obtain between the propositions may either actually obtain or not.

2 See the argument-diagrams in Stephen N. Thomas, Practical Reasoning in Natural Language, Third Edition (Englewood Cliffs, New Jersey: Prentice-Hall, Inc., 1986), p. 306.

3 See, for instance, Patrick Suppes, "Decision Theory", in The Encyclopedia of Philosophy, ed. Paul Edwards (New York: Macmillan Publishing Co., Inc., \& The Free Press, 1967), Vol. 2, p. 311 .

4 Carl Wellman, Challenge and Response: Justification in Ethics (Carbondale: Southern Illinois University Press, 1971), p. 57. See also Trudy Govier, Problems in Argument Analysis and Evaluation (Dordrecht, Holland: Foris Publications, 1987), pp. 69, 72.

5 William H. Halverson (A Concise Logic [New York: Random House, 1984]) defines an inductive argument as "an argument whose conclusion follows from its premises with a probability greater than 0 percent but less than 100 percent--or, as it is more commonly expressed, an argument whose conclusion follows from its premises with a probability greater than 0 but less than 1'" (p. 254). If this were the correct definition of an inductive argument, then such an argument would not involve favorable relevance. But it is questionable whether this is really what Professor Halverson meant to say, since it leads to such unacceptable consequences as that 'Few dogs have fleas' and 'My dog has fleas' are the premise and conclusion of an inductive argument, since the first of these propositions confers on the second a probability greater than 0 but less than 1 -in fact, less than $1 / 2$. Perhaps Professor Halverson meant to say 'degree of favorable relevance' instead of 'probability'.

6 Although the majority opinion on this question seems to be that the favorable relevance that is a necessary condition for an argument is attributed, some logicians say otherwise. For instance:

[In a proof, or argument,] "each proposition is a premise (which provides grounds or basis for the reasoning) or a conclusion (which follows from, or is logically derived from) the premise(s). The premises of an argument provide the evidence on the basis of which a conclusion is derived."-Henry Ehlers, Logic by Way of Set Theory (New York: Holt, Rinehart and Winston, Inc., 1968), p. 147.

"An argument in logic is a set of statements. Some of the statements serve as premises, or statements of evidence, and others serve as the conclusions that can be drawn from the premises."Louis O. Kattsoff, "Logic", in The World Book Encyclopedia, (Chicago: Field Enterprises Educational Corporation, 1967), Vol. 12, pp. 381-2.

“. . . a statement is called a conclusion when it is justified by other statements, which in turn are called evidence or reasons."-Peter T. Manicas and Arthur N. Kruger, Essentials of Logic (New York: American Book Co., 1968), p. 4. Quoted in Kenton F. Machina, Basic Applied Logic (Glenview, Illinois: Scott, Foresman and Company, 1978, 1982), p. 66.

"An argument is a series of statements arranged in such a way that one statement is a conclusion and at least one statement is a premise which supports the conclusion." "In every genuine argument, the premises provide some support for the conclusion." ". . . an argument, in order to be an argument, must have premises which support the conclusion ... ."-Barrie Wilson, The Anatomy of Argument (Washington, D. C.: University Press of America, 1980), pp $16,247,252$.

"In the context of logic, an argument is defined as a set of statements which is such that one of them (the conclusion) is supported or implied by the others (the premises)."-Robert Baum, Logic, Second Edition (New York: Holt, Rinchart and Winston, 1981), p. 87. 


\begin{abstract}
"An argument is a group of statements, one or more of which (the premises) support or provide evidence for another (the conclusion). . . ."-T. Edward Damer, handout for his workshop "Using the Fallacies to Teach Critical Thinking", Conference 88 on Critical Thinking, Christopher Newport College, Newport News, Virginia, April 10 , 1988 , p. 1
\end{abstract}

7 Cf. Baum, op. cit., p. 87: “An argument is an argument if it satisfies the above definition [namely, "a set of statements which is such that one of them (the conclusion) is supported or implied by the others (the premises)"'], even if no one has ever thought of it, let alone intended that it be used to prove something.'

8 Here are two instances of a spectator's becoming an arguer:

[1] "There is an argument in what they say, only they don't see it." (Perry Weddle, "Deductive/Inductive", Informal Logic Newsletter, Vol. ii, No. 1 [November, 1979], p. 2, col. 2.) It is not "they" but the speaking observer who is the arguer.

[2] Suppose I find a piece of paper with the sentence

1) All men are rational.

written on it. At some other time (earlier or later) I hear on the radio

2) All U.S. presidents are men.

And at some other time still I read on my classroom blackboard

3) All U.S. presidents are rational.
I would be a poor logician not to recognize that 1 and 2 jointly entail 3 . There are no explicit or implicit indicators here. There is no specifiable author to claim explicitly or implicitly that and how 1 and 2 relate to 3 . Yet I judge these sentences to constitute a (valid) deductive argument. . . . (George Englebretsen, "Freeman on Deduction/Induction", Informal Logic, Vol. vi, No. 1 [January, 1984], p. 27, col. 2.)

James B. Freeman ("Reply to Englebretsen", Informal Logic, Vol. vi, No. 2 [December, 1984], p. 39, col. 2) denies that there is any argument here at all. He is right, in that there is no argument until the spectator creates one. But after the spectator says, "Yet I judge these sentences to constitute a (valid) deductive argument", there is an argument; and the arguer is the spectator.

9 The preceding paragraph of the text is derived from an unpublished manuscript by the present author and Thomas E. Gilbert, What is an Argument? An Inquiry in the Philosophy of Logic (1979), pp. 122-126.

${ }^{10} \mathrm{Cf}$. Baum, loc. cit.: " . . . even if someone intends that a certain set of statements be used to prove something, that set of statements does not constitute an argument unless it satisfies the definition" - -i.e., unless some of the statements support or imply another.

11 The preceding paragraph is derived from Bowles and Gilbert, loc. cit.

GEORGE BOWLES

DEPARTMENT OF PHILOSOPHY THE GEORGE WASHINGTON UNIVERSITY WASHINGTON, D.C. 20052. 